\title{
Reading The Idea of History through The Principles of Art: Collingwood on Communication and Emotions
}

$\underline{\text { Abstract }}$

While Collingwood's Idea of History (IH) is an excellent resource for defending history's autonomy, its invocation is not without problems. If history deals only in reflective thought, how can it encompass irrational action? How can history reconcile its subjective method of imagination with its claim to objectivity? The most successful solutions to these problems, such as those proposed by D'Oro and Mink, appeal to Collingwood's greater philosophical system, but they typically attribute him a restrictive and unintuitive view of historical inquiry. We are left with a historical practice that is less equipped to address the problems we intuitively want it to solve - those dealing with past human experience as it actually occurred. Using The Principles of Art (PA), I present an interpretation of Collingwood's philosophy of history in which emotions are communicable between individuals. His theory of art defines artistic creation as a process 
in which unconscious emotions are harnessed and transformed into conscious emotions, which can then draw another individual into an imaginative experience that 'repeats' or 'is identical with' the artist's original experience. We therefore acquire an account of historical inquiry that permits the interpretation of emotionally-driven actions. In this interpretation, the a priori imagination becomes an irreducible faculty of everyday human activity, a means of interpreting fellow agents in our social environments; and the onus is transferred to the natural sciences to justify their encroachment into this irreducible activity at the foundation of human experience and society.

\section{$\underline{\text { Keywords }}$}

Collingwood, history, emotions, thought, art, communication

The Idea of History $(\mathrm{IH})$, since its publication, has played a central role in philosophical considerations of historical studies. Its importance has emerged in virtue of its defence of history as a discipline deserving epistemological and methodological autonomy from the natural and mathematical sciences. Additionally, the 'Epilegomena' proffers a number of curious and controversial philosophical theses concerning the nature of historical knowledge and method, and the objects of historical study. 
One of the most important claims of IH is that history properly concerns itself with objects 'altogether different in kind' to those of the natural sciences. ${ }^{1}$ Collingwood distinguishes between the inside and outside of an event. The outside is 'everything belonging to it which can be described in terms of bodies and their movements', while the inside is 'that in it which can only be described in terms of thought'. ${ }^{2}$ The events studied by the natural sciences do not have an inside in the aforementioned sense:

The processes of nature can therefore be properly described as sequences of mere events, but those of history cannot. They are not processes of mere events but processes of actions, which have an inner side, consisting of processes of thought; and what the historian is looking for is these processes of thought. ${ }^{3}$

Only humans are the objects of historical knowledge. Humans are the only animals whose actions are the expressions of their thoughts. Animals, generally, are motivated by 'mere impulse and appetite'. ${ }^{4}$ This is not to say that all aspects of human behaviour are the subject-matter of history. Collingwood states that certain aspects of human experience are natural events which do not possess an inside:

These irrational elements are the subject-matter of psychology. They are the blind forces and activities in us which are part of human life as it consciously experiences itself, but are not parts of the historical process: sensation as distinct from thought, feelings as distinct from conceptions, appetite as distinct from will. ${ }^{5}$

${ }^{1}$ R. G. Collingwood, The Idea of History, (Oxford: OUP, 1994), 217.

2 Ibid., 213.

${ }^{3}$ Ibid., 214.

${ }^{4}$ Ibid., 216.

${ }^{5}$ Ibid., 231. 
These aspects of experience — sensation, feelings, appetite—are more akin to the objects of inquiry in the natural sciences than those in history, since they belong to the physiological organism, and not to the realm of thought. These aspects of experience belong to the 'flow of immediate consciousness', whereas thought is 'something more than immediate consciousness':

Thought itself is not involved in the flow of immediate consciousness; in some sense it stands outside that flow ... [O]ne and the same act of thought may endure through a lapse of time and revive after a time when it has been in abeyance. ${ }^{6}$

As can be seen, 'thought' is a technical term for Collingwood. Its unique property, re-enactability, is especially important for Collingwood's theory of history, since the method used by the historian to discern the thoughts of past events is 'the re-enactment of past thought in the historian's own mind':

Suppose [the historian] is reading the Theodosian Code, and has before him a certain edict of an emperor ... [H]e must see the possible alternatives, and the reasons for choosing one rather than the other; and thus he must go through the process which the emperor went through in deciding on this particular course. Thus he is re-enacting in his own mind the experience of the emperor; and only in so far as he does this has he any historical knowledge ... ${ }^{8}$

\footnotetext{
${ }^{6}$ Ibid., 287.

${ }^{7}$ Ibid., 215.

${ }^{8}$ Ibid., 283.
} 
In order to obtain historical knowledge of an object, person, or event, the historian must imaginatively relive the thought process of the past agent concerned. This is not possible for natural events or physiological aspects of human actions, but is essential for historical knowledge.

Collingwood further specifies the kind of thought he takes to be re-enactable: '[To] become subject-matter for history, it must be an act not only of thought but of reflective thought, that is, one which is performed in the consciousness that it is being performed. ${ }^{9}$ The historian must discover the thoughts that motivated human processes, excluding any thinking that is not deliberately undertaken, by re-enacting them in one's own mind.

Finally, Collingwood discusses the criterion of historical truth. He defines it as an activity of a priori imagination, which 'gives the historical narrative or description its continuity ${ }^{\prime 0}$ : '[O]ur authorities tell us that one day Caesar was in Rome and on a later day in Gaul; they tell us nothing about his journey from one place to the other, but we interpolate this with a perfectly good conscience. ${ }^{11}$ The a priori imagination performs the structurally necessary role of filling gaps in the historical narrative that cannot be directly inferred from the evidence, providing the account with an internal consistency,

\footnotetext{
${ }^{9}$ Ibid., 308.

${ }^{10}$ Ibid., 241.

${ }^{11}$ Ibid., 240.
} 
even an internal necessity. Collingwood compares this to the use of imagination in fiction:

A man writing a novel composes a story where parts are played by various characters. Characters and incidents are all alike imaginary; yet the whole aim of the novelist is to show the characters acting and the incidents developing in a manner determined by a necessity internal to themselves. The story, if it is a good story, cannot develop otherwise than as it does; the novelist in imagining it cannot imagine it developing except as it does develop. Here, and equally in all other kinds of art, the a priori imagination is at work. ${ }^{12}$

When constructing a historical narrative, one uses the same imaginative apparatus as a novelist. Historical construction is prevented from extrapolating into fantasy by being threaded through certain fixed points of evidence, such as interpreted statements of historical authorities, or material remains.

The above constitutes a basic outline of the most pertinent claims when connecting Collingwood's philosophy of history and philosophy of art. In the next section, I outline some objections concerning Collingwood's philosophy of history, which I eventually solve using his Principles of Art (PA).

\section{Problems in The Idea of History}

12 Ibid., 242. 
The objections arising among readers of Collingwood's IH are well chronicled. Here I focus on a narrow subset of these, which I believe can be resolved by re-interpreting IH through PA:

- (a) His definition of thought as the subject-matter of history does not allow consideration of actions motivated by impulse or emotion;

- (b) His definition of a priori imagination as the criterion of truth makes historical knowledge subjective and ungrounded.

\subsection{All History is the History of Thought}

By defining thought so as to exclude immediate consciousness, sensations, feelings, and appetites, Collingwood would seem to preclude historians from considering human actions that are impulsive or emotionally motivated. Thought is taken to be selfconscious, deliberate, reasoned, and reflective, suggesting that Collingwood prescribes solely rational conduct as the subject-matter of history. The objections are obvious: historical agents are not exclusively motivated by the practical conclusions of their rational thought. Human life is emotional as well as intellectual, with many historical decisions being attributable to fear, love, or anger. Human life is impulsive, with many actions not being specifically chosen or deliberate, but last-minute, or poorly thoughtthrough. These actions enter just as easily into the course of historical events as do 
deliberate, rational actions, and a full understanding of the past relies on taking the former into consideration when reconstructing the causal chain of events. Our accounts of human actions should contain not only a narrow subset of their activities, but the whole range, including emotions, impulses, and chance. How can Collingwood provide a satisfying account of human history, which is threaded through with emotional reactions and convictions, impulse and chance, and the irrational behaviour that results?

\subsection{The Criterion of Truth is the A Priori Imagination}

Another major problem is Collingwood's criterion of historical truth, the a priori imagination. Collingwood explicitly likens imagination in the construction of historical narratives to imagination in the construction of fictional narratives. This has led to criticism of Collingwood for proposing a highly subjective and idiosyncratic method, based on the imagination of the historian at work. Although Collingwood attempts to mitigate this subjectivity by introducing necessary fixed data points with which imaginatively constructed narratives must be reconciled (e.g. physical evidence, authoritative accounts), he subsequently confesses that 'in history, just as there are properly speaking no authorities, so there are properly speaking no data' ${ }^{13}$ Historians are

${ }^{13}$ Collingwood, Idea of History, 243. 
responsible for assessing the accuracy or reliability of historical authorities, as well as the interpretation or significance of material remains:

[The historian's account] cannot derive its validity from being pegged down ... to certain given facts. That description represented an attempt to relieve him of the responsibility for the nodal points of his fabric, while admitting his responsibility for what he constructs between them. In point of fact, he is just as responsible for the one as for the other. Whether he accepts or rejects or modifies or reinterprets what his so-called authorities tell him, it is he that is responsible for the statement which, after duly criticizing them, he makes. The criterion that justifies him in making it can never be the fact that it has been given him by an authority. ${ }^{14}$

If the fixed data points used to verify the imaginative account do not fit, they can be interpreted as unreliable. This creates a reversal in the order of priority between the $a$ priori imagination and the 'fixed points' it is being threaded through. It becomes difficult to see how Collingwood's account of historical construction and verification is prevented from extrapolating into arbitrary fancy. Without fixed data, the historian is radically free to interpret events as they wish. How can history justify itself as a truth-seeking enterprise while using an unscientific and non-inferential method for the acquisition of knowledge?

\section{Proposed Solutions}

${ }^{14}$ Ibid., 244. 
With ambiguities and obscurities littered throughout, scholars over the decades have asked how Collingwood's philosophy of history can still be of use to defenders of the independence and validity of history. Arguably, the most successful attempts to resolve these issues have appealed to the greater philosophical system of which Collingwood's philosophy of history is a part. The theses found in IH, they claim, cannot be taken in isolation, because they belong to a much broader philosophy of a fundamentally systematic thinker. Two such attempts, those of D'Oro and Mink, propose in different ways that Collingwood intended to delineate history, confining it to human activity resulting from rational thought. As thoughtful as they are, both accounts leave us with a vastly reduced and limited framework of historical inquiry.

\subsection{D'Oro and Descriptive Metaphysics}

D'Oro bases her analysis of IH on the theory of philosophy proposed in Collingwood's Essay on Philosophical Method ${ }^{15}$ and Essay on Metaphysics. ${ }^{16}$ In these works, D'Oro reads Collingwood as outlining a theory of philosophy as 'descriptive metaphysics', whereby philosophy's purpose is to clarify the underlying assumptions and principles at work in a practice of knowledge or experience. To do this, the philosopher must begin

${ }^{15}$ R. G. Collingwood, An Essay on Philosophical Method, (Oxford: Clarendon Press, 1933).

${ }^{16}$ R. G. Collingwood, An Essay on Metaphysics, (Oxford: Clarendon Press, 1998). 
with an analysis of the practice — such as scientific inquiry, historical inquiry, or artistic creation — and 'regressively ascend' to the assumptions that are the conditions for its possibility. The word 'descriptive' is important for D'Oro's interpretation:

Collingwood believed the various forms of knowledge or experience to be 'attitudes of mind' which provide not mutually exclusive accounts of what exists but complementary explanatory principles on the basis of which what exists or what there is can be described. ${ }^{17}$

Philosophy describes the principles that regulate forms of inquiry. It does not provide ontologies; it examines various practices and describes the logically prior principles and assumptions that enable them. Rather than prescribing an ontology and then evaluating a knowledge-practice on that basis, Collingwood insists that experience must precede and inform philosophy. Since the world is necessarily perceived through the practices and concepts that structure our experience, 'there is no explanatory level that is ontologically basic', ${ }^{18}$ and this invalidates the attempt by one arena of knowledge and experience (e.g. science) to invade or colonise another (e.g. history).

D'Oro argues that precisely this descriptive metaphysics is found in IH:

Collingwood's philosophy of history is a study of the presuppositions that structure historical understanding and make historical knowledge possible. The fundamental

${ }^{17}$ G. D'Oro, Collingwood and the Metaphysics of Experience, (London: Routledge, 2002), 13.

${ }^{18}$ Ibid., 23. 
presupposition found by Collingwood in his philosophy of history concerns a cause-

effect relation based in rationality:

Just as natural scientists presuppose that reality is law-like ..., so too historians approach their subject matter by bringing to it the presupposition that historical reality is the product or construct of rationality and consequently that what occurs must be studied not as the manifestation of natural laws but as the expression of intelligent behaviour. ${ }^{19}$

This presupposition explains why Collingwood's historian focuses so narrowly on reflective thought: historical 'reality' is constituted by causes and effects that consist in beliefs, desires, and motivated action, and are connected logically rather than empirically. Historical explanation is intended to give an account of human activity by providing these rational or logical connections between events. According to D'Oro, this insulates Collingwood from criticisms that he held an overly intellectualist account of human action:

The charge that Collingwood's philosophy of history is overly intellectualistic because not all human doings are rational neglects to take into account the fact that in IH Collingwood is engaged in the project of explaining the domain of inquiry in history [which] comprises only deeds that are expressive of rational processes. ${ }^{20}$

D'Oro's account of Collingwood's thought is persuasive and coherent, but it leaves us with residual dissatisfaction concerning the role set out for historical

${ }^{19}$ Ibid., 106.

${ }^{20}$ Ibid., 113. 
knowledge. We are left with a history that is not equipped, or even willing, to address the problems we intuitively want it to solve. Human life, past and present, is an inseparable mixture of rationality, emotions, impulses, chance, and error; and it is the combination of these influences on historical processes that we seek to discover when we examine the past. The exclusion of these central factors leaves the historian who appeals to Collingwood for their epistemic and methodological independence with a significantly less powerful practice. If there is an interpretation of Collingwood's philosophy of history that would not separate aspects of human experience into artificially discrete categories, we ought to pursue it.

Furthermore, history as it is actually practised appears to take emotion and impulse into account. Historians are able to make the actions and outcomes of the past comprehensible on the basis of these factors, and one is not inclined to declare these histories substandard. If Collingwood intends to exclude these factors in his philosophy of history, this seems to betray his claim in the Essay on Philosophical Method that we ought to begin with the practice of history and work bottom-up towards the principles that govern it.

\subsection{Mink and Four Levels of Consciousness}


To explain the tensions in Collingwood's work, Mink uses PA's dialectical theory of mind. Collingwood takes consciousness to possess a dialectically ordered series of four levels. Mental acts of each level have as their objects the immediate experiences of the level below it, the latter of which are preserved and transformed in the process.

The most basic level is primary consciousness, or 'feeling'. This is a completely transient, momentary, unlocalised, undifferentiated awareness of organic states of the body, in which even sensation and emotion are not properly distinguished - a flux of immediate experience. Theoretical and practical aspects are not yet distinguished at this level, and it is experienced by humans and animals alike: 'The undifferentiated sensuousemotional flux which is the content of first-level consciousness is, by an act of attention which is an act of second-level consciousness, transformed into differentiated language. ${ }^{21}$

The second level is appetite and imagination. This is the awareness that one has a state of lack or need, but with no clearly identified object: second-level consciousness 'is an implicit form of thinking, insofar as it makes distinctions within what, at a lower level, is an undifferentiated field. ${ }^{22}$

Second-level consciousness identifies and delineates objects within the flux of experience; however, it does not compare its objects. This is the work of third-level

${ }^{21}$ L. O. Mink, 'Collingwood's Dialectic of History', History and Theory, 7.1, (3-37), 1968, 10.

${ }^{22}$ Loc. cit. 
consciousness, desire and perception, which identifies an entity or state as the object of appetite: '[T]he function of third-level consciousness is the apprehension of specific objects with awareness of their contrast. ${ }^{23}$

Finally, fourth-level consciousness is will and intellect, in which one becomes conscious of a desire, of oneself making a choice: '[O]nly at the fourth level can reasons be given for [propositions] and can they be affirmed for those reasons. ${ }^{24}$ This is where we reach inferential thought, and explicitly rational thinking. Looking back to Collingwood's IH, Mink takes the intellect (fourth-level consciousness) to be the reenactable subject-matter of history-thought.

The dialectical aspect of this theory of consciousness is important for Mink's interpretation. The 'feelings', 'emotions', 'sensations' of the first level, and the 'appetite' and 'imagination' of the second, are taken as raw-material for the higher levels of thought. They therefore survive in thought, although they are transformed. This is the basis of Mink's defence against criticisms that Collingwood over-intellectualised history by allowing for the re-enactment of thought exclusively, that he was unable to take into account the emotional or impulsive motivations for action:

[The historian] does re-enact the emotion which survives in and is transformed by consciousness in becoming an object for it. So far as such emotion does not thus survive, it cannot be recalled even by the person who felt it, and no theory of historical knowledge could possibly account for it ... Collingwood's true view

${ }^{23}$ Loc. cit.

${ }^{24}$ Loc. cit. 
was that the fourth level of consciousness can be re-enacted simpliciter; and the second and third levels can be re-enacted so far as (but no farther than) they have survived as objects of third- and fourth-level acts. ${ }^{25}$

Mink suggests that, although only fourth-level consciousness can be re-enacted by the historian, this does not render the historian's account overly intellectual nor devoid of emotion. Since emotions are the raw-material that is adopted and transformed by rational decision-making, emotions do enter into a historical account.

What kind of emotions eventually make their way into historical accounts? They must be mere remnants of lower-level emotions, transformed into something quite unrecognisable as emotion itself. Is this really an interpretation in which emotion per se is available for historians? What about emotionally-driven actions that do not pass through rational thought before they find expression? What about impulsive decisions? To the extent that lower levels of consciousness are not adopted as material for the intellect, emotions and impulses are not included in historical accounts.

Although Mink's interpretation includes emotion, the sense of 'inclusion' here is somewhat homeopathic, and the 'emotions' included seem a little ghostly, stripped of the passion and strength that makes them worthy of the name. When we complain that Collingwood neglects impulse and emotion, we mean that he neglects the lower levels of consciousness in and of themselves, not that he neglects their metamorphosed remnants in rational thought. The inclusion of intellectually transfigured emotions in historical

${ }^{25}$ Ibid., 13-14. 
accounts is hardly going to save Collingwood from charges of over-intellectualising history. Although Mink's interpretation permits the historian to engage with a much greater aspect of human motivation and activity than many prima facie readings of Collingwood, the result is still a vast reduction in the power and scope of historical analysis.

Mink's interpretation also suffers from the same weakness as D'Oro's, as he acknowledges:

What Collingwood means by 'history,' accordingly, cannot be understood as the class of things commonly called by that name. His concept is both broader and more restricted than the usual meanings of the term. Very little of what appears in some history books may be 'history' in his sense; on the other hand, things not usually recognized as historical inquiry may turn out to be so, parts of philosophy, for example, or the activity of clinical psychologists. ${ }^{26}$

If Mink's interpretation is accepted, then we must abandon our commonsense notions of history, excluding and including things that violate our intuitions on this category. Once again, this creates a conflict with Collingwood's notion-explained in An Essay on Philosophical Method - that one ought to start with the practice or experience, and describe the principles that guide it, coming to know better what we, in some sense, already knew.

Mink's explanation for Collingwood's notion of the a priori imagination is also dissatisfying. According to Mink, the a priori imagination is 'nothing but an early and

${ }^{26}$ Ibid., 20. 
unsuccessful attempt to formulate the notion of an absolute presupposition' ${ }^{27}$ Referring to Collingwood's Essay on Metaphysics (1940), Mink identifies Collingwood's a priori imagination with his theory of 'absolute presuppositions', the main statement of the latter being found in this later work. A constellation of absolute presuppositions is 'a system of concepts which provides the formal structure of experience'. ${ }^{28}$ They enter into historical analysis (and into Collingwood's philosophy of history) as follows:

They are widely as well as deeply shared; they are ways in which men may think alike as well as be alike in what they think. In fact, the theory of absolute presuppositions is intended by Collingwood as a logical instrument for the analysis of the foundations of civilization and of the dynamics of historical change ... The historical understanding of civilization thus requires the analysis of the a priori conceptual schemes implicit in the dominant thought of an epoch, and of the structure of conflicting conceptual systems and fragments of systems within an epoch. ${ }^{29}$

Mink resolves the issues of subjectivity and arbitrariness of the a priori imagination by suggesting that the latter is a prototype of an aspect of Collingwood's metaphysics: the necessarily contextually-situated nature of all knowledge and inquiry. Although Mink indicates genuine similarities between Collingwood's absolute presuppositions and his $a$ priori imagination, classifying the former as an 'unsuccessful' formulation of the latter is unsympathetic. Statements of the a priori imagination in IH are directly contradicted in his theory of absolute presuppositions. For example, the former is unique to historical

27 Ibid., 28.

28 Ibid., 24.

${ }^{29}$ Ibid., 25. 
thinking whereas the latter is a feature of all experience. In any case, I hope to provide a more generous and consistent account using PA.

\section{The Principles of Art as a Solution}

\subsection{Collingwood's Philosophy of Art}

In PA, Collingwood's task is to dispel common misunderstandings of art and discover its true nature. He finds art to fundamentally involve the expression of emotion.${ }^{30}$ When one expresses an emotion, one's consciousness is raised:

At first, he is conscious of having an emotion, but not conscious of what this emotion is. All he is conscious of is a perturbation or excitement ... From this helpless and oppressed condition he extricates himself by doing something which we call expressing himself. ${ }^{31}$

The expression of emotion makes the bearer aware of the nature of their emotion. Until they have expressed their emotion, they cannot know how they feel.

The emotions expressed in artistic creation are capable of being experienced by non-artists alike. This process fundamentally involves the imagination. ${ }^{32} \mathrm{By}$ 'imagination', Collingwood does not mean make-believe. Imagination is 'indifferent to

${ }^{30}$ R. G. Collingwood, The Principles of Art, (Oxford: Clarendon Press, 1938), Ch. VI. ${ }^{31}$ Ibid., 109-110.

${ }^{32}$ Ibid., Ch. VII. 
the distinction between the real and the unreal'. ${ }^{33}$ It is a faculty that allows us to

construct, out of what is available to our senses, a coherent picture:

When I look out of the window, I see grass to right and left of the mullion that stands immediately before me; but I also imagine the grass going on where this mullion hides it from my sight. ${ }^{34}$

Imagination is an everyday mental process of filling in gaps to form a sensible understanding of our environment. This faculty also plays a role in aesthetic appreciation. Collingwood takes the work of art not to be the observable product, but rather the corresponding mental entity in the artist's mind. The observable product is simply a communicative aid in allowing the expression of this mental entity: 'The noises made by the performers, and heard by the audience, are not the music at all; they are only means by which the audience, if they listen intelligently (not otherwise), can re-construct for themselves the imaginary tune that existed in the composer's head. ${ }^{35}$ Collingwood compares this reconstructive process to that of a lecture audience:

[T] he listening which we have to do when we hear the noises made by musicians is in a way rather like the thinking we have to do when we hear the noises made, for example, by a person lecturing on a scientific subject ... The noises are meant to assist us in achieving what he assumes to be our purpose in coming to hear him lecture, that is, thinking this same scientific thesis for ourselves ... In each case,

33 Ibid., 136.

${ }^{34}$ Loc. cit.

${ }^{35}$ Ibid., 139. 
what we get out of it is something which we have to reconstruct in our own minds, and by our own efforts. ${ }^{36}$

Observable works of art allow us to reconstruct the experience in the artist's mind: a 'total imaginative experience' beyond the mere sensuous elements. To appreciate art, one proceeds from elements 'given in sensation' to that which must be 'imaginatively reconstructed' ${ }^{37}$ Artistic creation and aesthetic appreciation combined are therefore a process in which emotions felt by the artist are transmuted into an observable product, the latter of which is sensorily perceived by an audience, who use it to imaginatively reconstruct — and thereby experience — the artist's original emotions. What kind of emotions are these?

In Collingwood's dialectical theory of mind, the two lowest levels of consciousness are both referred to as 'feeling', but these are 'two different kinds of experience each of which goes by that name':

[W]e describe the specialized activities of thus 'feeling' colours, sounds, scents, and the like collectively as the senses, and the common activity which is specialized into them as sensation. Secondly, we speak of feeling pleasure or pain, anger, fear, and so forth. Here also we have a general activity of feeling specialized into various kinds, each with its proper specification of what we feel. It is not, clearly, of quite the same kind as sensation; to distinguish it, let us call it emotion. $^{38}$

\footnotetext{
${ }^{36}$ Ibid., 140-141.

${ }^{37}$ Ibid., 148-149.

${ }^{38}$ Ibid., 160.
} 
There are indications here that emotions of a certain sort - the second-level, conscious emotions communicated in art-are reproducible and capable of imaginative reconstruction by another individual, an indication that has great significance for interpretations of IH:

[The] sensum I felt a second ago is not now present to me; it has vanished, carried away by the flux of sensation ... In the same way, future sensa, possible sensa, other people's sensa, are sensa not present to me here and now, and are therefore not things whose relations with each other, or with the sensa now present to me, I am in a position to discuss. ${ }^{39}$

'Emotions', on the other hand,

differ from sensa chiefly in not being wholly fluid and evanescent; so that any one of them may be retained in the mind as an object of attention after the moment of sensation is past ... [T] here is a special activity of mind correlative to them, and ... this is what we generally call imagination. ${ }^{40}$

Emotions have the property of communicability. One way in which communication can occur is through imaginative reconstruction in appreciation of art.

Much of the language used in IH to describe the 'immediacy' of experience inaccessible to historians is used in PA only in reference to the first-level of consciousness, consisting in sensations, and not in reference to second-level emotions. In PA, Collingwood describes the former as 'a level of experience below the level of

${ }^{39}$ Ibid., 168-169.

${ }^{40}$ Ibid., 170. 
thought', 'carried away by the flux of sensations', 'no longer there to be compared with [a] successor'. The latter are described as 'new orders of emotions: emotions that can arise only in a thinker' which 'may be retained in the mind as an object of attention after the moment of sensation is past'. ${ }^{41}$ It is 'sensation' that resembles the uncommunicable experience described in IH. In IH, feeling is carried away by 'the stream of immediate experience'. ${ }^{42}$ '[T] hought', however, is available for historical analysis by literally one and the same thought being revived in the historian's own mind.

Collingwood emphasises in PA that the exact same emotions are reconstructed in the minds of the artist's audience. Discussing potential issues of identifying the artist's emotion and the emotion reconstructed by an audience, Collingwood writes:

How is anyone to know that the imaginative experience which the spectator, by the work of his consciousness, makes out of the sensations he receives from a painting 'repeats', or is 'identical' with, the experience which the artist had in painting it? ... [T] he only assurance we can have is an empirical and relative assurance, becoming progressively stronger as conversation proceeds, and based on the fact that neither party seems to the other to be talking nonsense ... [W] can never absolutely know that the imaginative experience we obtain from a work of art is identical with that of the artist. In proportion as the artist is a great one, we can be pretty certain that we have only caught his meaning partially and imperfectly. But the same applies to any case in which we hear what a man says or read what he writes. And a partial and imperfect understanding is not the same thing as a complete failure to understand. ${ }^{43}$

\footnotetext{
${ }^{41}$ Ibid., 163-170.

${ }^{42}$ Collingwood, Idea of History, 293.

${ }^{43}$ Collingwood, Principles of Art, 309.
} 
Collingwood claims that art is, essentially, language. Therefore, the epistemic problem of whether an artist and their audience share the same emotion is identical to the epistemic problem of interlocutors sharing the same idea. To know that the emotions reconstructed in aesthetic experience are the same that motivated the artist, it suffices that communication does not break down, that one continues to see—or feel—sense in that which one is reconstructing. We therefore have good reason to interpret Collingwood's philosophy of history as involving the possibility of reconstruction by historians of second-level, conscious emotions of past agents.

Further similarities exist. In PA, aesthetic appreciation of artistically-expressed emotion relies on a precondition of the perceiver:

If a poet expresses, for example, a certain kind of fear, the only hearers who can understand him are those who are capable of experiencing that kind of fear themselves. Hence, when someone reads and understands a poem, he is not merely understanding the poet's expression of his, the poet's, emotions, he is expressing emotions of his own in the poet's words, which have thus become his own words. ${ }^{44}$

The experiences expressed in art are communicated only insofar as the perceiver already has the capacity for these experiences. In exactly the same way, Collingwood tells us in IH that, to re-enact a past thought, the historian must be 'pre-adapted to become its host',

${ }^{44}$ Ibid., 118. 
since for everyone, there will be ways of thinking in which one has 'a readier sympathy' and others in which one 'is not, or no longer, or not yet, able to think. ${ }^{45}$

With these analogies abounding, it would seem that, when Collingwood refers to sensations, feelings, and appetites as being necessarily excluded from historical accounts, he intends to limit this exclusion to the most basic form of experience- - the flux of sensation. Additionally, by explicitly acknowledging the natural-language ambiguity of the term 'feeling', perhaps Collingwood alludes to misinterpretations of previous essays (later published in $\mathrm{IH}$ ) which declared such aspects of experience as 'feeling', 'sensation', and 'emotion' as unavailable to historians, and separated 'thought' as standing 'outside that flow'. ${ }^{46}$ It was as a result of imprecise language that he unwittingly communicated the exclusion of all emotion from historical accounts.

The language of PA also provides an interpretation of Collingwood's a priori imagination. Collingwood consistently refers to the process of artistic-emotional interpretation as 'imaginative reconstruction' or as involving the 'imagination', and I believe it is no coincidence that Collingwood uses the same wording for his criterion of historical truth. Just like imaginative reconstruction in PA, the a priori imagination is not associated with that which is 'fictitious or unreal', although it can be used for makebelieve. Collingwood tells us in IH that the very same faculty is used by the novelist and

${ }^{45}$ Collingwood, Idea of History, 304, 218.

${ }^{46}$ Ibid., 287. 
'in all other kinds of art', strengthening the connection still. ${ }^{47}$ The a priori imagination need only be understood as a basic and ubiquitous interpretive faculty of the human mind, one that is present in a wide variety of activities, including art, history, language, and everyday perception. Determining whether something that is imaginatively constructed is identical to that of which it is an attempted reconstruction (be this in language, art, or history) is assured simply by those involved continuing to see coherence in each other's outward behaviour, and the avenue of communication remaining open. In language, this consists in one's not perceiving the other as speaking nonsense; in history, it consists in the coherence and plausibility (also a lack of nonsense) of the narrative, given the evidence.

\subsection{Collingwood's Philosophy of Experience}

The re-enactability of second-level consciousness is crucial for Collingwood's philosophy of experience. He allocates artistic expression and emotional communication a central position in the life of individuals and society.

Collingwood places the distinction between good and bad art in the artist's truthfulness or falsity of consciousness:

${ }^{47}$ Ibid., 241-243. 
A bad work of art is the unsuccessful attempt to become conscious of a given emotion ... It is the malperformance of the act which converts what is merely psychic (impression) into what is conscious (idea) ... [C]onsciousness which thus fails to grasp its own emotions is a corrupt or untruthful consciousness ... What [the artist] has done is either to shirk [his emotion] or dodge it: to disguise it from himself by pretending either that the emotion he feels is not that one but a different one, or that the person who feels it is not himself, but someone else. ${ }^{48}$

This is no trivial matter for Collingwood. False consciousness leaks into other areas of

life:

[B] ad art is not a thing we can afford to tolerate. To know ourselves is the foundation of all life that develops beyond the merely psychical level of experience. Unless consciousness does its work successfully, the facts which it offers to intellect, the only things upon which intellect can build its fabric of thought, are false from the beginning. A truthful consciousness gives intellect a firm foundation upon which to build; a corrupt consciousness forces intellect to build on a quicksand. ${ }^{49}$

Collingwood does not consider art to be a specialised activity of a subsector of

society. Within his philosophy is a deep connection between artistic creation and the selfawareness and interpersonal expression of all people:

[T] he effort towards expression of emotions, the effort to overcome corruption of consciousness, is an effort that has to be made not by specialists only but by everyone who uses language, whenever he uses it. Every utterance and every gesture that each one of us makes is a work of art. It is important to each one of us that in making them, however much he deceives others, he should not deceive himself. ${ }^{50}$

${ }^{48}$ Collingwood, Principles of Art, 282-283.

${ }^{49}$ Ibid., 284.

${ }^{50}$ Ibid., 285. 
Artistic expression is undertaken by any individual engaging in honest, conscious expression of their experiences. These expressive acts result in observable products that, when interpreted by other individuals, constitute the communication that rests at the heart of communal ways of life. False consciousness in expression thus presents a genuine danger to society, since 'the life of a community depends for its very existence on honest dealing between man and man'. ${ }^{51}$ This honesty cannot exist when people dwell in false consciousness:

In so far as consciousness is corrupted, the very wells of truth are poisoned. Intellect can build nothing firm. Moral ideals are castles in the air. Political and economic systems are mere cobwebs. Even common sanity and bodily health are no longer secure. But corruption of consciousness is the same thing as bad art. ${ }^{52}$

Honest expression and successful interpretation of second-level conscious emotions are therefore not merely possible in Collingwood's philosophy; they are crucial for the very existence and functioning of society, and for its constituents, morality, political and economic institutions, and even mental and physical health. This reveals a profound philosophy of experience in which human reality, including all that springs from the intellect, is based on a fundamental communicative-imaginative faculty of the human mind: the interpretation, from observable products, of the expressed experiences-

${ }^{51}$ Loc. cit.

52 Ibid., 284-285. 
emotional at basis - of our fellow human beings, and the corresponding honest expression of our experience.

This provides further evidence that Collingwood intended to include emotions in the material available for historical inquiry; but it also provides an overwhelmingly original answer to a deep problem in the philosophy of history: why ought we to respect the methodological and epistemic autonomy of history? Placing expression and interpretation at the core of experience, Collingwood invites us to question the ordering of epistemic priority between history and the natural sciences.

If honest communication - expression and interpretation - constitutes the basis for all reality of higher-levels of consciousness (the intellect, morality, politics, economics, sanity, physical health), then it must be understood as an irreducible practice of human beings. In suggesting that the historical method is the very same method as that by which we come to understand the basic emotions and experiences of the members with whom we share our social environment, Collingwood imbues it with a significant element of epistemic priority. History need not follow the pattern of inference or meet the standards of evidence of the natural sciences, since it is a wholly different activity, and it is one that occupies a central structural position in the understanding, organisation, and functioning of the lives of human beings.

There may even be reason to subordinate natural science to history, epistemically. We experience and interpret beliefs, desires, emotions, regrets, and their expression, in 
our daily lives. We do so in such a way, in fact, that our daily lives would be unimaginable, dysfunctional, without them. These experiences are "the only things upon which the intellect can build its fabric of thought,${ }^{53}$ including scientific knowledge. It is therefore out of daily experience that the natural sciences spring, not vice versa. Why take the latter - itself an abstraction from daily experience — and turn it back on its originator, everyday experience, in an attempt to invalidate it?

Here we find our way back to the a priori imagination as the criterion of historical truth. Just as language and emotional communication rely for their validity on a mere continuation of coherence given witnessable utterances or observable products, the validity of history and its criterion of truth—-the a priori imagination—relies on nothing more than its continued coherence given the evidence. Since such expression and interpretation are fundamental and irreducible, the a priori imagination is not vulnerable to accusations of subjectivity. It is as objective as can be-as objective as the basis of the intellect and common sanity.

With this understanding of Collingwood's overarching philosophy of experience, many puzzles of IH dissolve. We acquire an account of historical inquiry that allows the interpretation and accommodation of emotionally driven actions; we have an intuitive

${ }^{53}$ Ibid., 284. 
explanation of the a priori imagination; and, most significantly, we have a fundamental justification for history's autonomy as an arena of inquiry and knowledge. With honest communication of interpretable, conscious emotions at the centre of social life and all institutions built upon it, the a priori imagination, as a means of interpreting fellow agents in our social environment, becomes a basic, irreducible aspect of everyday life and experience. Indeed, Collingwood's statement in IH takes on a new significance: 'historical thinking is an original and fundamental activity of the human mind. ${ }^{54}$ The onus is hence transferred to the colonising natural sciences to justify their encroachment into this basic and irreducible aspect of human life and activity.

Parysa Clare Mostajir, University of Chicago parysa@uchicago.edu

${ }^{54}$ Collingwood, Idea of History, 247. 